\title{
Influence of Vanadium Content on the Toughness and Hardness of High-al- loyed Cr-Mo Steel
}

\author{
A. Todić ${ }^{1}$, D. Čikara ${ }^{1}$, B. Pejović ${ }^{1}$,T. Todić ${ }^{1}$, V. Mićić ${ }^{2}$, I. Čamagić ${ }^{1}$ \\ 'Faculty of Technical Sciences, University of Pristina, 7. Kneza Milosa Str. 38220 Kosovska Mitrovica, Serbia \\ 2 Faculty of Technology Zvornik, Karakaj bb 75400 Zvornik, Republic of Srpska, Bosnia and Herzegovina
}

\begin{abstract}
Characteristics of air hardening steel are high hardness and low impact toughness. In order to increase the impact toughness while retaining replace with the high hardness value numerous research added. One of the ways to achieve this is the alloying of specified steel with vanadium and application of appropriate heat treatment. Vanadium affects the solidification process of these alloys by narrowing of the temperature interval of crystallization. In addition, vanadium formed $V_{6} C_{5}$ carbides that block the growth of austenitic dendrites and structure makes fine-grained. Vanadium which forms $V_{6} C_{5}$ carbides is partly distributed between present phases in the steel, carbide $(\mathrm{Cr}, \mathrm{Fe})_{7} \mathrm{C}_{3}$ and austenite. Also, the presence of vanadium can enable the formation of $(\mathrm{Cr}, \mathrm{Fe})_{23} \mathrm{C}_{6}$ carbide and its precipitation in austenite during the cooling process. In local areas around fine carbide particles, austenite is transformed into martensite. In other words vanadium reduces the amount of remained austenite and so improves hardenbility of the steel. In this way, better technical characteristics of these steels are obtained.
\end{abstract}

\section{KEYWORDS}

Vanadium, Impact Toughness, Hardness, Microstructure.

\section{Introduction}

Testing of the characteristics of high alloyed $\mathrm{Cr}$-Mo steel was carried out by changing of vanadium content from 0.5 to $3 \%$. According to the chemical composition and carbon content, this alloy belongs to the alloyed cast iron, but according to ENISO10020 added it falls into alloyed steel castings.

The as cast microstructure of this steel consists of primary austenite dendrites, which can be partially or completely transformed. It is expected that with the increasing of the vanadium content, the alloy hardness and wear resistance decreases, and the impact toughness increases.

The basic problem with these steels is low impact toughness. Until very recently, the solution to increase the impact toughness was sought in getting of the complete martensite structure, that can be achieved by quenching of steel from the temperature of about $1000^{\circ} \mathrm{C}$.

In recent years, the research goes in the direction of investigation of the influence of alloying elements such as molybdenum, manganese and particularly vanadium [1, 2, 3].

Vanadium affects the crystallization process, as it moves the liquid and solid lines

*Corresponding author: A. Todić, E-mail address: todics@open.telekom.rs 
toward higher temperatures.

In this paper, the research focus is set to study the influence of vanadium on the structure, hardness and toughness of the specified steel.

\section{The Influence of Chemical Composition on Structure and Properties of Cr-Mo Steel}

In order to investigate the influence of chemical composition on the structure and properties of this steel is necessary to define the influence of certain elements on the properties of steel.

\subsection{Effect of Chromium}

Chromium is the basic alloying element in steels with higher hardness and wear resistance, because its addition establishes several metallurgical functions.

Chromium reacts with carbon to form hard wear resistant carbides, prevents the transformation of austenite to perlite during cooling of castings and affects the structure of the steel metal matrix by closing of, area in the phase diagram [4].

Carbides $\mathrm{Cr}_{7} \mathrm{C}_{3}$ type and $\mathrm{Cr}_{23} \mathrm{C}_{6}$ can be alloy with iron to form the interstitial phases $(\mathrm{Cr}, \mathrm{Fe})_{7} \mathrm{C}_{3}$ and $(\mathrm{Cr}, \mathrm{Fe}){ }_{23} \mathrm{C}_{6}$. Best toughness and hardness have the structures containing carbide $(\mathrm{Cr}, \mathrm{Fe})_{7} \mathrm{C}_{3}$, which is formed in steel containing more than $6 \%$ of chromium. With the increase of chromium content eutectic point is shifted to lower concentrations of carbon. However, chromium does not increase hardenability but combined with higher carbon content increases the depth of the quenched layer.

\subsection{Effect of Vanadium}

The presence of vanadium, even in small concentrations, has a positive effect on high alloyed Cr-Mo steels.

Vanadium affects the solidification process of these alloys by narrowing of the temperature interval of crystallization. Namely, the crystals of $\mathrm{V}_{6} \mathrm{C}_{5}$ carbides are formed during the separation of primary austenite from the solution, blocking further growth of austenite dendrites and support the production of fine grained structures [5].

Besides it forms added, $V_{6} C_{5}$ carbides, similar to the molybdenum, vanadium, is partly distributed between present phases in the steel; carbide $(\mathrm{Cr}, \mathrm{Fe})_{7} \mathrm{C}_{3}$ and austenite.

The presence of vanadium enables the formation of $(\mathrm{Cr}, \mathrm{Fe})_{23} \mathrm{C}_{6}$ carbide and its precipitation in austenite during the cooling process. In local areas around fine carbide particles, austenite is trans- formed into martensite. In other words, vanadium reduces remained austenite and improves steel air-hardening. Vanadium concentration over 2.5\% significantly improves the impact toughness. Because of the relatively high ferro-vanadium price, it is added only when a particular quality castings is required.

\subsection{Effect of microstructure on the steel properties}

The microstructure determines the two most important characteristics of the wear-resistant material, hardness and toughness. Customizing content and arrangement of the phases and micro-constituents, present in the structure of steel, is possible to obtain the maximum value of hardness and toughness, or the optimal combination of these characteristics [6]. To clarify the influence of microstructure on the properties of steel, we will consider the basic constituents: carbides and metal matrix.

In terms of structure, this type of steel belongs to the ledeburitic steels. Because of dendritic segregation, crystallization of the ledeburitic steel starts with the separation of primary austenite crystals that containing less carbon, chromium and molybdenum than in the melt. Ledeburit is distributed as a network around the primary austenite crystals. After the solidification of ledeburit, shape, size and distribution of the proeutectic carbide cannot be changed by heat treatment, and solidification process is of essential importance for the steel properties.

At high-alloyed ledeburit, austenitic phase has a higher growth rate, so that the austenite formed a wrapper around carbide fibers and this structure result in higher chromium steel strength and toughness, compared to unalloyed or low alloyed ledeburitic micro-constituent.

Precipitation of secondary carbides, mostly $(\mathrm{Cr}$, $\mathrm{Fe}_{23} \mathrm{C}_{6}$, from austenite grains takes place during slow cooling or subsequent annealing [6]. At the very beginning, the precipitate is very fine and oriented along the border with eutectic $(\mathrm{Cr}, \mathrm{Fe})_{7} \mathrm{C}_{3}$ carbide and around the austenite grains boundaries.

The process of precipitation of secondary carbides reduces the chromium and carbon content in the metal matrix so that a higher percentage of austenite will be transformed to martensite. Such a phenomenon of secondary carbides has dual positive effect as follows: hard, fine dispersed phase is formed and the amount of residual austenite is re- 
duced $[7,8]$.

The main problem in production of high alloy $\mathrm{Cr}$ Mo steel castings is to keep high hardness and, at the same time, achieve good toughness.

To achieve this it is necessary that the metal matrix be a cubic martensite or even better bainite, without or with only a very small amount of retained austenite.

\section{Description of the Experiment}

For melting of the steel, induction furnace added of $250 \mathrm{~kg}$ capacity, was used. The samples for the experiments were cast into the sand molds. Molds are made according to the patterns that have the shape and dimensions in accordance to the impact toughness and hardness test standards. Castings were heat treated by hardening in controlled air flow and subsequent tempering. The tempering was done at two temperatures as follows:

- low temperature tempering at $250^{\circ} \mathrm{C}$, which removes micro-stresses, improves toughness and ductility of steel, compared to the hardened state, but keeps high strength and toughness that is required of wear resistant castings and,

- medium temperature tempering at $400^{\circ} \mathrm{C}$, which, also removes micro-stresses, but leads to the formation of bainitic structure, and therefore increase the impact toughness of steel.

Predicted chemical composition of the steel for this type of test was: $C=2.2 \%, C_{r}=12 \%, M o=1.2 \%$, while the vanadium changed as follows: for the first series $0.5 \% \mathrm{~V}$, second $1 \% \mathrm{~V}$, third $2 \% \mathrm{~V}$ and for the fourth series vanadium was $3 \%$. The chemical composition of samples I, II, III and IV series are in the Table I.

Surface of the samples, immediately after casting and heat treatment, is very rough so it was necessary to clean up cast samples and machined it to the standard test dimensions. Mechanical processing should be done with permanent cooling in order to avoid any change in the microstructure.

For testing of the impact toughness samples added of $55 \mathrm{~mm}$ long and $10 \times 10 \mathrm{~mm}$ cross section were prepared. Testing of impact toughness was performed using computerized pendulum Schenck-Trebel 150/300J. Pendulum computerization includes connecting of the force meter, detector of the fracture time and deformation gauge through the amplifier with an oscilloscope. As the fracture of the samples caused by impact is a very
Table 1: Chemical Composition of the Samples.

\begin{tabular}{|c|c|c|c|c|c|c|}
\hline \multirow[b]{2}{*}{ 営學 } & \multirow[b]{2}{*}{ 姜 } & \multicolumn{5}{|c|}{ Chemical Composition } \\
\hline & & C(\%) & Cr (\%) & Mo (\%) & $\mathbf{S}(\%)$ & $V(\%)$ \\
\hline 1 & I & 2.17 & 11.12 & 1.1 & 0.03 & 0.45 \\
\hline 2 & $\|$ & 2.19 & 11.01 & 1.12 & 0.03 & 0.91 \\
\hline 3 & III & 2.15 & 11.59 & 1.09 & 0.03 & 1.96 \\
\hline 4 & IV & 2.11 & 11.52 & 1.01 & 0.03 & 2.80 \\
\hline
\end{tabular}

short phenomenon (since 0.5 to $8 \mathrm{~ms}$ ), the role of the oscilloscope is to make the signal visible. Oscilloscope is then connected to a computer for processing signals obtained in the measurement.

For the purposes of hardness testing the samples of similar size as the impact toughness tests are made. Because of the relatively high hardness of the material, hardness testing was done by Rockwell C method on the Vexus SHR-150M device.

Analysis of the microstructure was performed under a light microscope Olympus GX41 that was equipped with software for image processing and phase analysis and on SEM microscope JEOL JSM$6610 \mathrm{LV}$. Prepara-tion of samples was carried out using standard metallographic procedure.

\section{Results and Discussion}

The testing results of steel with different contents of vanadium showed the expected results that are presented in the next tables.

\section{Effect of vanadium on the hardness}

Hardness testing was performed on six points of the sample so that the mean values for the relevant value was taken. Results of hardness testing are shown in Table II.

Table 2: The values of hardness.

\begin{tabular}{|l|l|l|l|} 
Serial Number & \multirow{2}{*}{ Sample Mark } & \multicolumn{2}{c|}{ Hardness (HRC) } \\
\cline { 3 - 4 } & \multicolumn{250}{c}{$\mathbf{5 0}^{\circ} \mathbf{C}$} & $\mathbf{4 0 0}^{\circ} \mathbf{C}$ \\
\hline 1 & I & 63.00 & 62.25 \\
\hline 2 & II & 60.30 & 60.50 \\
\hline 3 & III & 60.10 & 58.50 \\
\hline 4 & IV & 58.90 & 57.20 \\
\hline
\end{tabular}

From the table it can be seen that with increasing vanadium content in the alloy, hardness decreases, respectively, and more intensive when the 
samples were tempered at a temperature of $400^{\circ} \mathrm{C}$. When the tempering temperature was $250^{\circ} \mathrm{C}$ decrease in hardness is less severe, as seen in Figure 1. However, hardness remained at a relatively high level and the decrease of hardness is acceptable.

This reduction in hardness undoubtedly entails increasing of impact toughness.

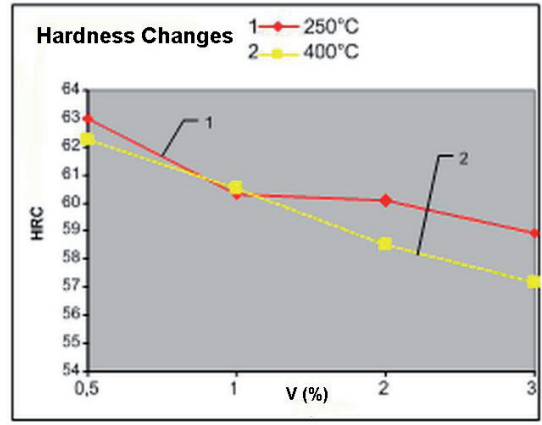

Fig. 1: Diagram of Hardness Changes

\section{Effect of vanadium on the impact toughness}

Impact toughness testing was performed on three samples from each series. The mean value of toughness measurements was taken as authoritative. Table III presents the results of impact toughness.

From the table it can be seen that with increasing of vanadium content increases the impact toughness values, especially at the samples from the fourth series (mark IV) containing $3 \% \mathrm{~V}$.

Table 3: The values of impact toughness.

\begin{tabular}{|l|l|l|l|} 
Serial Number & \multicolumn{2}{c|}{ Sample Mark } & \multicolumn{2}{c|}{$\begin{array}{c}\text { Toughness }\left(\mathbf{J} / \mathbf{c m}^{\mathbf{2}}\right) \\
\mathbf{2 5 0}{ }^{\circ} \mathbf{C}\end{array}$} & $\mathbf{4 0 0}{ }^{\circ} \mathbf{C}$ \\
\hline 1 & I & 2.37 & 5.45 \\
\hline 2 & II & 4.50 & 5.55 \\
\hline 3 & III & 6.45 & 6.96 \\
\hline 4 & IV & 7.15 & 8.71 \\
\hline
\end{tabular}

From the table it can be seen that with increasing of vanadium content increases the impact toughness values, especially at the samples from the fourth series (mark IV) containing $3 \% \mathrm{~V}$.

Increasing of impact toughness is more noticeable for the samples tempered at temperature of $400^{\circ} \mathrm{C}$ than for samples tempered at $250^{\circ} \mathrm{C}$ (Fig. 2). Increasing of impact toughness is significant, while the hardness remained on satisfactory high level.

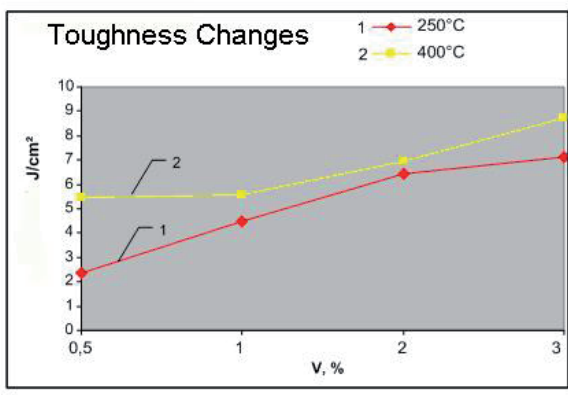

Fig. 2: Diagram of Toughness Changes

\section{Effect of vanadium on the structure}

With increasing of vanadium content, the radial distribution of $(\mathrm{Cr}, \mathrm{Fe})_{7} \mathrm{C}_{3}$ carbides becomes a dominant but the proportion of long directed lamellas and plates do not change.

Vanadium is soluble in both, eutectic carbide and austenite. In alloys containing 2-3\% of vanadium, austenite, is largely transformed to bainite during cooling. In the structure also present added in a small amount of martensite, mainly along the border with eutectic carbide.

Figure 3 shows the structure of the sample made under a light microscope, while Figure 4 shows micrographs of the structures made on SEM. In order to determine the chemical composition of the present phases, the EDS analysis was performed.

From the SEM micrographs it is evident that the metal matrix of the alloy is immersed with fine carbides of alloying elements. A carbide network has a rounded shape with a small amount of carbide rods. Locations where an EDS analysis was done are marked with the counts 1 to 4 . Count 1 is a point on the carbide grains dispersed in metal matrix, while points since 2 to 4 refer to the points in carbide network.

The analysis in count 1 added which relates to the carbides of metal matrix, shows that the carbides contain $24 \%$ of carbon, $10 \%$ of chromium, $81 \%$ of iron, $0.21 \%$ of vanadium and a small amount of manganese that could not be precisely determined. However, carbon content is close to his stechiometric content in $\mathrm{Fe}_{3} \mathrm{C}$ carbide, indicating the possibility that the carbides type $\mathrm{M}_{3} \mathrm{C}$ are formed in the metal matrix. EDS analysis shows that in the crystal lattice of this carbide a small number of iron atoms are replaced by atoms of chromium and manganese. Manganese builds $\mathrm{Mn}_{3} \mathrm{C}$ carbide that is similar to $\mathrm{Fe}_{3} \mathrm{C}$. It has orthorhombic lattice and 
is most likely that the carbide $(\mathrm{Fe}, \mathrm{Mn})_{3} \mathrm{C}$ is precipitated in a steel metal matrix.

Counts 2, 3 and 4 refer to the eutectic carbide network and EDS analysis shows that these are the M7C3 type carbides.

Table IV presents the chemical composition of the tested phases in weight percentages, while Table $V$ shows the chemical composition of the tested phases in atomic percentages. On the figure 5 and 6 the chemical spectar done by EDS analysis was shown.

Based on the SEM micrograph, EDS analysis in figure 5 and 6 and data that are given in Tables IV and $V$ added it can be concluded that the structure consists of bainitic metal matrix with a small amount of martensite and retained austenite and carbide phase, type $(\mathrm{Cr}, \mathrm{Fe})_{7} \mathrm{C}_{3}$.

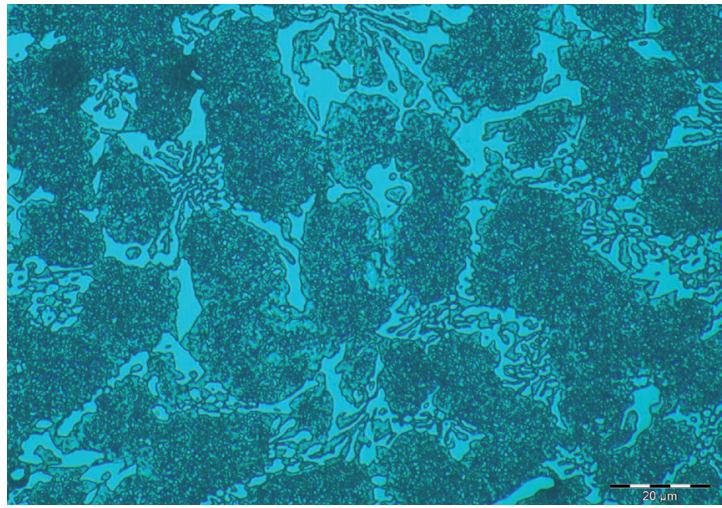

Fig. 3: The Structure of the Sample made by Light Microscopy.

Table 4: Chemical composition of the tested samples in weight percentage.

\begin{tabular}{|c|c|c|c|c|c|c|c|c|}
\hline \multirow{2}{*}{ Samples } & \multicolumn{8}{|c|}{ Elements Content (weight \%) } \\
\hline & C & Si & V & $\mathbf{C r}$ & Fe & Ni & Mo & Total \\
\hline Count 1 & 7.24 & 0.63 & 0.21 & 9.99 & 81.04 & 0.00 & 0.87 & 100.00 \\
\hline Count 2 & 13.07 & 0.00 & 2.42 & 42.50 & 40.69 & 0.00 & 1.33 & 100.00 \\
\hline Count 3 & 12.21 & 0.00 & 2.23 & 42.43 & 41.00 & 0.00 & 2.12 & 100.00 \\
\hline Count 4 & 13.25 & 0.00 & 2.47 & 42.16 & 40.07 & 0.00 & 2.06 & 100.00 \\
\hline
\end{tabular}

Table 5: Chemical composition of the tested samples in atomic percentages.

\begin{tabular}{|c|c|c|c|c|c|c|c|}
\hline \multirow{2}{*}{$\begin{array}{l}\text { Series of } \\
\text { samples }\end{array}$} & \multicolumn{7}{|c|}{ Elements Content (atomic \%) } \\
\hline & C & Si & V & $\mathbf{c r}$ & $\mathrm{Fe}$ & $\mathbf{N i}$ & Mo \\
\hline Count 1 & 22.72 & 1.21 & 0.22 & 7.94 & 67.46 & 0.00 & 0.44 \\
\hline Count 2 & 40.94 & 0.00 & 1.72 & 29.90 & 26.79 & 0.00 & 0.66 \\
\hline Count 3 & 42.77 & 0.00 & 1.67 & 29.38 & 25.49 & 0.00 & 0.69 \\
\hline Count 4 & 42.40 & 0.00 & 1.63 & 29.77 & 25.44 & 0.00 & 0.77 \\
\hline
\end{tabular}

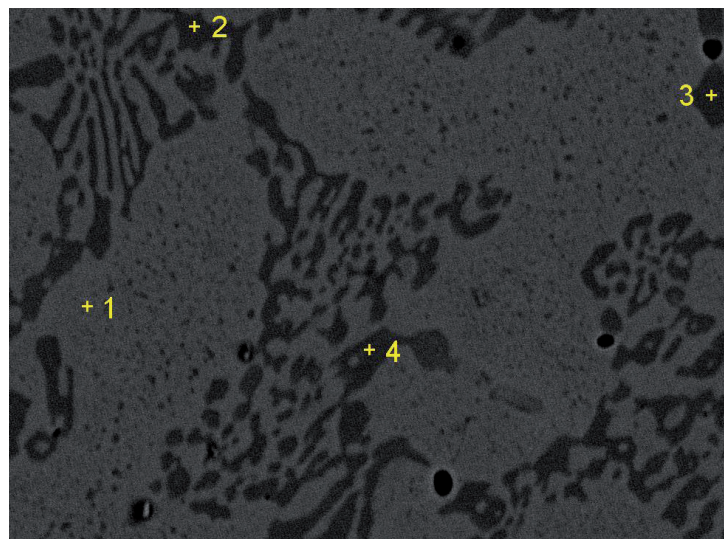

Fig. 4: SEM Micrograph of the Sample.

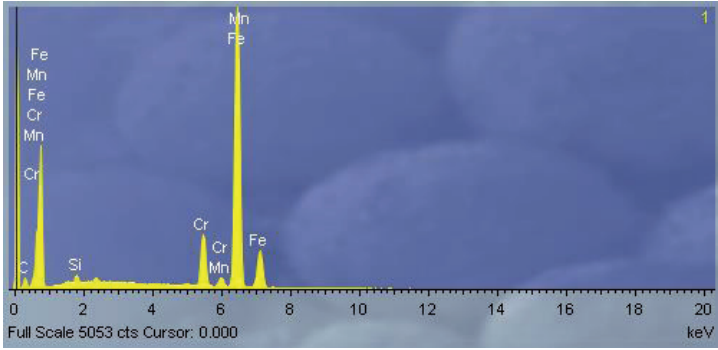

Fig. 5: EDS Spectrum at Point 1

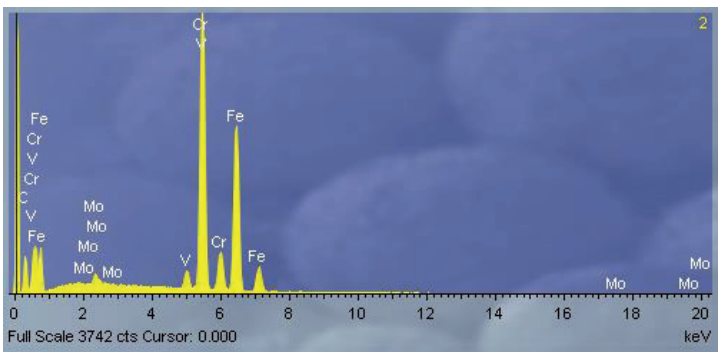

Fig. 6: EDS Spectrum at Point 1

Content (weight \%) 


\section{Potential of Application}

This type of steel, because of its high hardness and satisfactory impact toughness, and therefore high wear resistance, can have a wide application area.

Parts and components that are exposed to abrasive, impact-fatigue or combined wear are used in mining, metallurgy, engineering constructions, paper industry, mechanical engineering, etc. Assortment of these parts are: parts of mining machinery (excavator teeth and tooth covers, crusher plates for stone coal and ore minerals, mills hammers, plates and linings, separation grates, etc.). In addition, this material can be used for making bunkers lining for abrasive materials, sand blasting shovels, mud pumps housing, molds for briquetting of coal and steel turnings, tanks and transporters caterpillars, and many other parts. Mills hammers and jaw crushers plates are exposed to abrasive wear combined with the high compressive stress and impulse impact loads. Therefore, the materials used to manufacture these parts should, in addition to hardness, have a good impact toughness.

\section{Conclusion}

In this paper, the influence of vanadium to the microstructure, hardness and toughness of the steel with $2.2 \%$ of carbon, $12 \%$ of chromium and $2.0 \%$ of molybdenum was discussed. Generally, with increasing vanadium content, the structure becomes finer affecting the mechanical properties of the steel i.e. the hardness and impact toughness. Vanadium content in the steel added was varied: as first series added is $0.5 \% \mathrm{~V}$, for the second series is $1 \% \mathrm{~V}$, for the third series is $2 \% \mathrm{~V}$ and for the fourth series is 3\%. A total of 20 samples were casted. The chemical compositions the samples of I, II, III and IV are showed in Table I.

Vanadium content higher than 3\% have a negative influence on the properties of steel (significant decrease in hardness) and therefore the research with a higher percentage of vanadium were not included.

It can be seen that an increase of vanadium has a positive effect on the structure and the properties of materials. Testing samples of Series I showed high hardness while the impact toughness is extremely small. Samples of the Series II showed a slight reduction in hardness while the impact toughness is greater than the toughness of Series I. Hardness of the samples of Series III follows this trend and is slightly lower than the Series I and II, while the impact toughness slightly increased compared to Series I and for Series II. Series IV showed the best properties. Hardness is reduced compared to Series III but is still satisfactory, while the increasing added the impact strength is significant.

It is well known that these materials have extremely high hardness but their impact toughness is very small, so their use is limited. From this research added can be concluded that the composition of the steel with $3 \%$ of vanadium have impact strength which is, for this type of material added is extremely high, while the hardness decreased slightly but remained at an acceptable level. These mechanical properties enable new applications of steel with chemical composition corresponding to Series IV.

\section{References}

[1] Vodopivec F., Šuštatrčić B., Vojvodić T. J., Kosec G., Charpy notch toughness and hardness of reheated martensite and lower bainite, Metalurgija. vol. 49, no. 3, 2010, p.149-154.

[2] Wang Y., He D., Yu C., Jiang J., Effect of vanadium on the Properties of Fe-Cr-C Hardfacing Alloy, Hanjie Xuebao/Trasaction of the China Welding Institution, vol. 31, no. 5, 2010, p.61-64.

[3] Radović N., Koprivica A., Glišić D., Fadel A., Drobnjak Đ., Influence of $\mathrm{Cr}, \mathrm{Mn}$ and $\mathrm{Mo}$ on the Structure and Properties of $\mathrm{V}$ Micro- alloyed Medium Carbon Forging Steels, MjoMJournal of Metalurgy. vol .16, no. 1, 2010, p.1-9.

[4] Schuman H., Metallography, translated from German, Faculty of Technology and Metallurgy, Belgrade, 1989.

[5] Radulović M., Fiest M., Peev K., Effect of Rare Earth Elements on Micro-structure and Properties of High Chromium White Iron, Materials Science and Technology, 1994, vol. 10, no. 12, 1057-62 CODEN: MSCTEP; ISSN: 0267-0836.

[6] Baker T.N., Processes, microstructure and properties of vanadium microalloyed steels. Materials Science and Technology, vol. 25, no. 9, 2009, p.1083-1107.

[7] Yang F., Haisheng S., Junfei F., Zhou X., An investigation of secondary carbides in the spray-formed, high alloyed Vanadis 4 stell during tempering, Elsevier, Materials characterization, vol 59, 2008, p. 883-889.

[8] Todić A. Čikara D., Todić T., Čamagić I., Influence of Vanadium on Mechanical Characteristics of Air-Hardening Steels, FME Transactions, vol. 39 no. 2, 2011 p.49-54. 